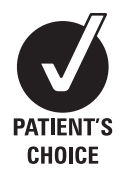

${ }^{1}$ INRETS, LESCOT, Bron, France

${ }^{2}$ Hôpital Nord, Service de Neurologie, CHU Saint-Etienne, France

${ }^{3}$ INSERM EMI 342, UCBL1 Lyon \& UJM, Saint-Etienne, France ${ }^{4}$ Université Lyon I, Hospices Civils de Lyon, Hôpital Neurologique Pierre Wertheimer, Service de Neurologie C, Lyon, France ${ }^{5}$ CNRS, UMR 5229, Centre de Neurosciences Cognitives, Lyon, France

\section{Correspondence to}

Miss Maud Ranchet, Institut National de Recherche sur les Transports et leur Sécurité (INRETS), Laboratoire d'Ergonomie et de Sciences Cognitives pour les Transports (LESCOT), 25, Avenue François Mitterrand, Case 24, Bron Cedex 69675, France: maud.ranchet@inrets.fr

Received 14 December 2009 Revised 8 June 2010

Accepted 9 June 2010 Published Online First 27 August 2010

\title{
Impaired updating ability in drivers with Parkinson's disease
}

\author{
Maud Ranchet, ${ }^{1}$ Laurence Paire-Ficout, ${ }^{1}$ Claude Marin-Lamellet, ${ }^{1}$ Bernard Laurent, ${ }^{2,3}$ \\ Emmanuel Broussolle $e^{4,5}$
}

\section{ABSTRACT}

Objective Driving activity requires major involvement of executive functions. The main objective of our study was to determine whether mental flexibility and the updating of information in working memory are affected in drivers with mild to moderate Parkinson's disease (PD).

Methods The study included 25 patients, aged 58-76, with mild to moderate PD and 25 healthy controls matched for age, sex and education, with an average mileage of over $3000 \mathrm{~km} /$ year. Neuropsychological tests were conducted to assess global cognitive abilities, to evaluate updating (via the n-back task), flexibility (via the plus-minus task) and information-processing speed (via the Stroop test). Three different scenarios were developed on a driving simulator. Participants were asked to recall road signs (updating task), indicate the shape or colour of road signs according to road side (flexibility task) and to brake at the same time as the car ahead (information-processing speed task) while driving. Results An updating impairment was found in PD patients in the n-back and simulator tasks; patients recalled significantly fewer road signs. No notable differences were observed between groups in the plus-minus task or in the simulator task evaluating flexibility. There was no significant difference between patients and controls in information-processing speed tasks. Regression analysis showed that the Trail-Making test (B-A) accounted for $40.7 \%$ of the variation in $P D$ drivers' simulator task updating score.

Conclusion The updating function is clearly impaired in drivers with mild to moderate PD, while mental flexibility remains unaffected. This study demonstrates the interest of using the Trail Making Test and simulator tasks to assess PD drivers.

\section{INTRODUCTION}

Parkinson's disease (PD) is a progressive neurological disorder characterised by both motor and non-motor symptoms. Cognitive symptoms are a major feature which can appear even in the early stages of PD. ${ }^{1}{ }^{2}$ Impairments of working memory and executive functions are frequently observed, ${ }^{23}$ as are disturbances in high-level executive functions such as planning and problem solving. ${ }^{4}$ Deficits are also described in lower-level executive functions such as mental flexibility (set shifting), ${ }^{2} 6$ inhibition of automatic responses ${ }^{7}$ and the manipulation and updating of verbal and visuospatial representations. ${ }^{3} 58$ These functions are all particularly important in novel, dynamic or demanding situations, ${ }^{9}$ and most driving scenarios fall into this category. ${ }^{10}$ Updating, for instance, is particularly important for refreshing information such as road signs. Mental flexibility is also essential for adapting driving behaviour to changing contexts on the road, ${ }^{11}$ where operations must be performed quickly, within a time frame.

$\mathrm{PD}$ patients may give up driving at some point in the course of the disease, ${ }^{12}$ but they often continue to drive during the first decade of their illness. ${ }^{13-15}$ Although there are no well-established epidemiological data on the crash risk for this population, ${ }^{16}$ an increased risk of accidents has been reported in PD. ${ }^{17} 18$ For the above reasons, a better understanding of the relationship between cognitive and driving abilities is necessary in order to identify patients whose driving abilities may be potentially impaired. ${ }^{19}$

The main objective of this study was to determine whether executive functions such as updating of information in working memory and mental flexibility are affected in drivers with mild to moderate PD. To do so, neuropsychological tests and specific tasks using a driving simulator were used. To our knowledge, no study has hitherto investigated these functions independently using simulated driving in this population. Informationprocessing speed was also measured, since a slowing of this ability could well explain poorer performances in PD patients. ${ }^{20}$ Our secondary objective was to examine the impact of updating and flexibility tasks on mean speed and speed variability. A further aim was to provide cognitive tools to assist clinicians in evaluating drivers with PD.

\section{METHODS \\ Subjects}

Twenty-five patients with PD (age range 58-76 years) and 25 healthy controls matched for sex, age, education level and driving experience were included in the study (table 1).

The sex ratio was 19 men/ 6 women in both groups. PD patients were recruited by a neurologist (EB) at the Department of Neurology. The following exclusion criteria were applied for patients: treatment with anticholinergic medication; global cognitive deterioration based on a score of 24 or less in the Mini Mental State Examination; moderate to severe depression based on a clinical interview and a score of 17 or more in the Beck Depression Inventory; and presence of neurological disorders other than idiopathic PD. Inclusion criteria were as follows: idiopathic PD according to the UK's Parkinson's Disease Brain Bank standards, ${ }^{21}$ normal visual acuity. Patients were in the mild to moderate stages of PD, based on disease duration, the Hoehn and Yahr scale and the motor section of the Unified Parkinson's Disease Rating Scale (UPDRS). Patients 
Table 1 Demographic and clinical characteristics of Parkinson's disease patients and controls

\begin{tabular}{lcccc}
\hline & $\begin{array}{l}\text { Parkinson's } \\
\text { disease } \\
\text { patients, } \\
\mathbf{n = 2 5} \\
\text { mean (SD) }\end{array}$ & $\begin{array}{l}\text { Controls, } \\
\mathbf{n = 2 5 ,} \\
\text { mean (SD) }\end{array}$ & $\begin{array}{l}\text { Two-tailed } \\
\text { p-value* }\end{array}$ \\
\hline Age (years) & $65.4(5.2)$ & $66.7(4.4)$ & 0.325 \\
Years of education & $13.9(3.7)$ & $13.6(2.8)$ & 0.937 \\
Years of driving & $45.1(6.0)$ & $46.6(6.1)$ & 0.533 \\
Mini Mental State Examination (MMSE) & $28.1(1.4)$ & $29.1(0.9)$ & $\mathbf{0 . 0 0 6}$ \\
score & $9.0(4.7)$ & $6.0(2.6)$ & $\mathbf{0 . 0 0 8}$ \\
Beck Depression Inventory score & $7.2(2.9)$ & $6.1(3.3)$ & 0.223 \\
Epworth Sleepiness Scale score & $1.8(0.4)$ & - & \\
Hoehn and Yahr stage & $6.4(5.4)$ & - & \\
Disease duration in years & $58.9(7.7)$ & - & \\
Disease onset age in years & $14.9(5.2)$ & - & \\
Unified Parkinson's disease Rating & & & \\
Scale-motor score & $346.5(267.7)$ & - & \\
Levodopa dosage (mg/day)† & & &
\end{tabular}

Values in bold are significant

*Student $t$ test or Mann-Whitney $U$ test.

†Levodopa (+dopa-decarboxylase inhibitor) without dopaminergic agonists.

were assessed while on medication. ${ }^{22}$ Thirteen patients were rated at Hoehn and Yahr stage 1.5, 10 at stage 2, 1 at stage 2.5 and 1 at stage 3 . Twenty PD patients were treated by levodopa; 9 $(45 \%)$ had mild to moderate motor fluctuations. Overall, 18 patients were on dopamine agonists (pergolide, pramipexole, ropinirole, piribedil), 5 were on COMT inhibitors (entacapone), 2 on $\mathrm{MAO}$ inhibitors (selegiline) and 1 on amantadine. One patient was not on any medication.

Controls were recruited through different local associations for older people. They had no physical, visual or hearing impairments. There was no history or current evidence of psychiatric disorders, neurological impairment, drug or alcohol dependence, or dementia.

Participants were not taking medication known to impair driving performance, other than treatments taken by patients to control PD symptoms. All subjects held valid driving licences and were regular drivers (with a minimum annual driving mileage of $3000 \mathrm{~km} /$ year). None of the participants complained of decreased driving abilities. The study was approved by the local biomedical ethics committee. Written informed consent was obtained from all subjects in accordance with Helsinki guidelines.

\section{Neuropsychological assessments}

Neuropsychological testing was conducted to investigate the various cognitive processes related to driving abilities, with particular focus on updating, mental flexibility and informationprocessing speed.

\section{Global cognitive assessment}

Measures of global executive function were obtained using the Trail Making Test (TMT B-A). ${ }^{23}$ The ability to inhibit an automatic response, visual memory and short-term storage capacity were assessed via the Stroop test (inhibition cost index), ${ }^{24}$ Benton Visual Retention Test ${ }^{25}$ and a digit span task, ${ }^{26}$ respectively. Maintenance of relevant information (phonological loop), was measured using Baddeley's Working Memory digit-span task in single condition, in which participants were required to recall digits sequences of the same length for $2 \mathrm{~min}$.

Updating: n-back task

This computerised task included three conditions: in the control condition (0-back), participants were asked to respond as quickly as possible on presentation of the number 50. In the two remaining conditions, they had to evaluate the similarity of each item to the one presented $n$-items previously ( $\mathrm{n}$ being a prespecified integer $(n=1, n=2))$. Correct response times and errors were measured in each condition. In our study, the 2-back condition was taken as a measure of updating ability. ${ }^{27}$

Mental flexibility: the plus-minus task

On the first list, participants were instructed to add 3 to each number and write down their answers. On the second list, they were instructed to subtract 3 from each number. On the third list, the participants were required to alternate between adding 3 to and subtracting 3 from the numbers. We used shift cost as a measure of mental flexibility, calculated as being the difference between mean completion times of the third list and mean completion times from the first two lists. ${ }^{11}$

Information-processing speed: Stroop test

In the colour-naming condition of the Stroop test, participants had to name the colour of each rectangle as quickly as possible. This condition was designed to evaluate information-processing speed.

\section{Driving simulator and experimental tasks}

The experiment was conducted using the INRETS fixed-base simulator, a Renault Espace car with a manual gearbox, with hidden instrumentation and sensors. The vehicle has a threescreen front view with a horizontal visual field of $150^{\circ}$ and a vertical visual field of $40^{\circ}$ (figure 1). Before performing the driving test, subjects were invited to familiarise themselves with the simulator by driving it for $20 \mathrm{~min}$. Three scenarios were developed to assess updating, mental flexibility ${ }^{28}$ and information-processing speed while driving.

In the updating and flexibility tasks, the participants drove on a road with little traffic and a speed limit of $90 \mathrm{~km} / \mathrm{h}$.

\section{Updating task}

In this task (a $24 \mathrm{~km}$ scenario), participants were asked to recall, in any order, the last three road signs of each series while driving (free recall). They subsequently had to answer different questions about information given on the last three road signs (cued recall). Three series of four, six or eight road signs respectively varied randomly. The updating score, calculated by adding the free recall and cued recall scores, represented our updating measure (figure 2).

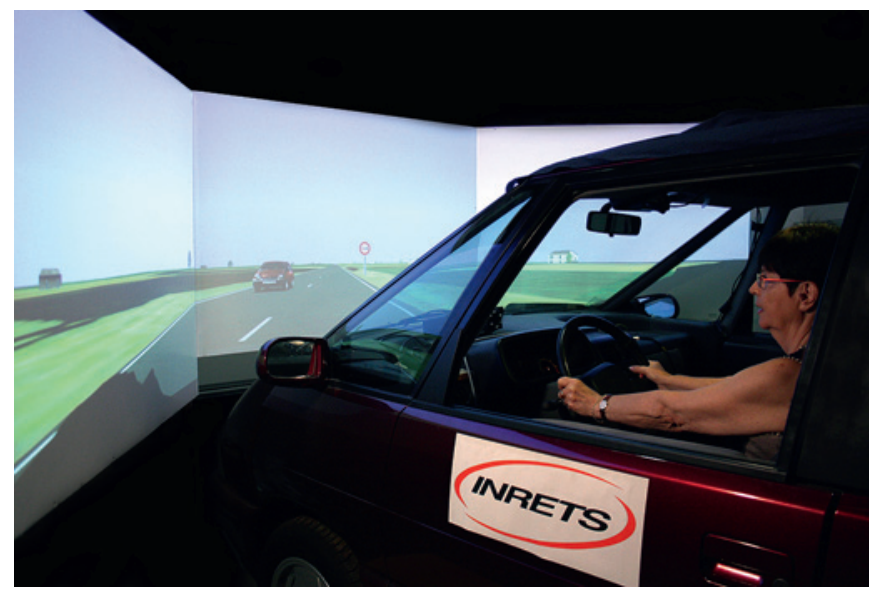

Figure 1 View of the driving simulator. 


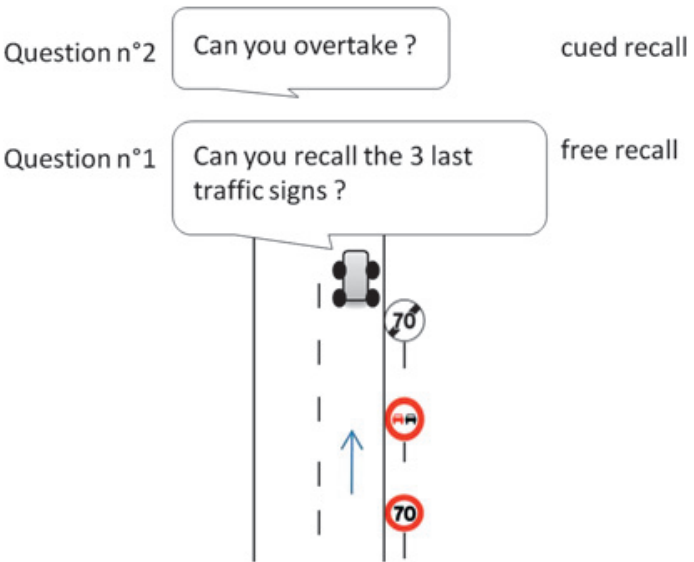

Figure 2 Diagram of the driving simulator updating task scenario. See details in the Methods section.

\section{Flexibility task}

There were two conditions in this task. In the condition without alternation (a $13.8 \mathrm{~km}$ scenario), participants had to state the shape of the road sign (rectangular, triangular, square or round) placed on the right-hand side of the road (session 1). They then had to state the dominant colour of the road sign (blue, green, red or brown) placed on the left-hand side of the road (session 2). Each session included three practice trials and 16 tests. In the condition with alternation (session 3 , requiring mental flexibility), a $10.9 \mathrm{~km}$ scenario, participants were asked to state the shape of the road sign if it was on the right-hand side, and to indicate the colour of the road sign if it was on the left. Signs were placed alternately on the right or left of the road. The condition with alternation included four practice trials and 32 tests. Flexibility cost constituted our mental flexibility measure; this was obtained by calculating the difference between mean reaction times of correct trials in the condition with alternation and mean reaction times of correct trials from the first two sessions in which no flexibility was required (figure 3).

\section{Information-processing speed task}

This task included two conditions, one static and one dynamic. In the static condition, participants were asked to press the accelerator pedal, and to respond to the appearance of the brake lights of the car ahead, by braking as quickly as possible. In the dynamic condition, drivers had to perform the same task while driving on a straight road in a low-information environment

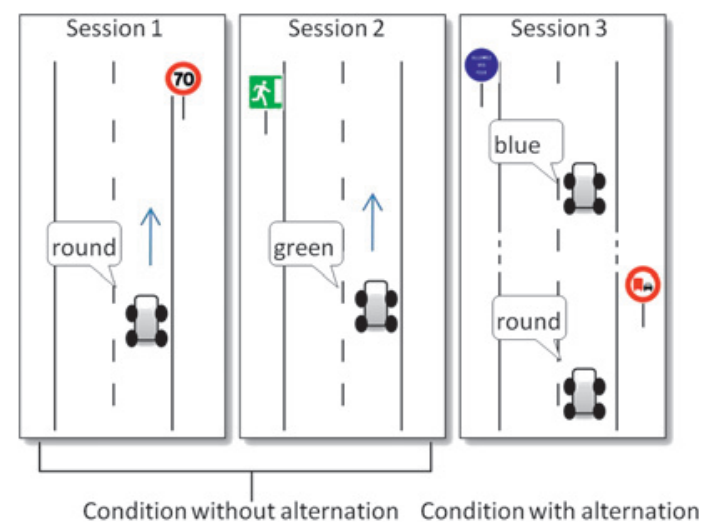

Figure 3 Diagram of the driving simulator flexibility task scenario. See details in the Methods section. using a $3 \mathrm{~km}$ scenario. They were asked to drive at approximately $70 \mathrm{~km} / \mathrm{h}$. Each condition included three practice trials and 12 tests. The distance between the car ahead and the driver was $60 \mathrm{~m}$. Brake lights lit up for $2 \mathrm{~s}$, and the interstimuli interval varied randomly from 8 to $12 \mathrm{~s}$. Information-processing cost, calculated as being the difference between reaction times in the dynamic condition and those of the static condition, was designed as our information-processing speed measure.

\section{Driving speed and speed variability}

Mean driving speed and speed variability (mean SD of speed) were measured in both updating and flexibility tasks. According to the literature, slow speed associated with high speed variability are indicative of decreased driving ability. ${ }^{15}$ 29-31 A reduction in speed variability is interpreted as an adaptation of driving behaviour when a concurrent task is present. ${ }^{31}$

\section{Procedure}

The experimental part of the study was divided into two phases for all participants. In phase 1 , they were examined by a general medical practitioner in order to verify medical inclusion criteria. In phase 2 , on a separate day, neuropsychological simulated driving tests were carried out in a fixed order over a period of 3 to $4 \mathrm{~h}$ with two rest breaks. Driving simulator experiments lasted approximately $20 \mathrm{~min}$ for the updating task, 30 min for the flexibility task and $5 \mathrm{~min}$ for the braking task. PD patients were tested in the morning while on medication. There was approximately 1 month between neurological testing of patients and their inclusion in the study. The time between inclusion and the experiment was approximately 1 month for both patients and controls.

\section{Data analysis}

Differences between the $\mathrm{PD}$ and control groups regarding demographic and clinical data were analysed using an independent two-tailed Mann-Whitney U. Differences between the two groups regarding neuropsychological and driving simulator data were analysed using an independent one-tailed $t$ test or Mann-Whitney $U$, depending on variable normality (Shapiro-Wilk test). In the n-back task, reaction times and errors were analysed using repeated-measure ANOVAs with group as the between-subjects factor (patients/controls), and condition as the within-subjects factor (0-back/1-back/2-back).

We used the Wilcoxon test to compare mean speed and speed variability performances between the flexibility task (condition with alternation) and the updating task. We also compared mean speed and speed variability performances in the condition without alternation to that of the condition with alternation, again using the Wilcoxon test, in order to investigate the effect of flexibility on driving performance.

Spearman correlation coefficients between UPDRS motor scores and updating scores, and flexibility and informationprocessing costs were calculated to ensure the absence of any association between motor functions and cognitive performances. Correlation analyses (Pearson product moment correlation and Spearman rank correlation coefficient) were used to measure the association between the neuropsychological variables and on-simulator updating scores for all participants. All significant correlated variables were then introduced into a stepwise regression analysis in order to determine which variables explain the variation in updating score for the simulator updating task for PD patients.

An $\alpha$-level of 0.05 was applied to all our statistical analyses. All analyses were performed with SPSS 17.0 statistical software (SPSS, Chicago, Illinois). 


\section{RESULTS}

\section{Neuropsychological performances}

In the light of neuropsychological results, the cognitive status of patients did not appear to be significantly impaired compared with controls (table 2). Global executive function (TMT), inhibition (Stroop-inhibition cost index) and verbal short-term storage (digit span) did not differ between PD patients and controls.

\section{Updating: n-back task}

ANOVA results showed that reaction times were significantly slower in patients (538.82 $\mathrm{ms} \pm 95.04)$ than in controls (489.70 ms \pm 70.23$)(\mathrm{F}(1,48)=4.32, \mathrm{p}=0.043)$. However, patients did not commit significantly more errors than controls (patients: $1.91 \pm 2.59$ vs controls: $0.56 \pm 0.72$ ). Specifically, participants were significantly slower and committed more errors when the level of complexity increased (for reaction times: $F(2,48)=83.73$, $p<0.010$; for errors: $F(2,48)=15.53, p<0.001)$. This was confirmed by a significant group $\times$ condition interaction for reaction times $(\mathrm{F}(2,48)=5.35, \mathrm{p}=0.025)$ and for errors $(\mathrm{F}(2,48)=$ $5.16, \mathrm{p}=0.028)$. PD patients and controls did not differ in the 0 -back condition for reaction times and errors. In the 1-back condition, no significant difference in reaction times was observed between the two groups, although patients committed

Table 2 Comparison of Parkinson's disease patients and controls in neuropsychological tests

\begin{tabular}{|c|c|c|c|}
\hline & $\begin{array}{l}\text { Parkinson's } \\
\text { disease } \\
\text { patients, } \\
\text { n=25, } \\
\text { mean (SD) }\end{array}$ & $\begin{array}{l}\text { Controls, } \\
n=25 \\
\text { mean (SD) }\end{array}$ & $\begin{array}{l}\text { One-tailed } \\
\text { p-value* }\end{array}$ \\
\hline \multicolumn{4}{|l|}{ Global cognitive assessment } \\
\hline \multicolumn{4}{|l|}{ Trail making test } \\
\hline Part A times (s) (1) & $44.6(16.8)$ & $45.2(15.8)$ & 0.433 \\
\hline Part B times (s) (2) & $91.9(38.1)$ & $75.9(28.3)$ & 0.090 \\
\hline Trail Making Test $(B-A)(2)-(1)$ & $47.3(36.9)$ & $30.8(20.6)$ & 0.084 \\
\hline Stroop test $†$-inhibition cost index & $66.0(33.1)$ & $53.8(22.0)$ & 0.097 \\
\hline Benton Visual Retention Test & $12.8(1.5)$ & $13.4(1.3)$ & 0.054 \\
\hline \multicolumn{4}{|l|}{ Baddeley's Working Memory dual task } \\
\hline Digit Span (n) & $5.6(0.9)$ & $6.0(1.2)$ & 0.092 \\
\hline $\begin{array}{l}\text { Digit span task-digits sequences } \\
\text { recalled }(n)\end{array}$ & $6.8(4.2)$ & $7.6(4.1)$ & 0.225 \\
\hline \multicolumn{4}{|l|}{ Updating: n-back task } \\
\hline \multicolumn{4}{|l|}{ 0-back } \\
\hline Response times (ms) & $418.2(60.1)$ & $411.4(59.4)$ & 0.688 \\
\hline Errors $\ddagger$ & $0.7(1.5)$ & $0.2(0.4)$ & 0.261 \\
\hline \multicolumn{4}{|l|}{ 1-back } \\
\hline Response times (ms) & $464.8(80.2)$ & $425.7(61.0)$ & 0.058 \\
\hline Errors $\ddagger$ & $0.7(1.7)$ & $0.1(0.2)$ & 0.038 \\
\hline \multicolumn{4}{|l|}{ 2-back } \\
\hline Response times (ms) & $733.5(189.1)$ & $632.1(133.8)$ & 0.033 \\
\hline Errors $\ddagger$ & $4.4(1.2)$ & $1.4(0.5)$ & 0.002 \\
\hline \multicolumn{4}{|l|}{ Flexibility: plus-minus task } \\
\hline Addition list completion times (s) (5) & $60.4(16.4)$ & $50.8(12.7)$ & 0.013 \\
\hline Subtraction list completion times (s) (6) & $83.7(29.5)$ & $65.4(22.8)$ & 0.005 \\
\hline Shift list completion times (s) (7) & $92.7(31.2)$ & $77.3(19.6)$ & 0.043 \\
\hline Shift cost $(7)-[(6)+(5)] / 2$ & $20.7(15.8)$ & $19.2(14.5)$ & 0.392 \\
\hline \multicolumn{4}{|l|}{ Information-processing speed: Stroop test $†$} \\
\hline Colour naming completion time (s) & $65.0(9.5)$ & $62.2(7.1)$ & 0.217 \\
\hline \multicolumn{4}{|c|}{$\begin{array}{l}\text { Variables in italics are the variables of interest. Values in bold are significant. } \\
\text { *Student } t \text { test or Mann-Whitney U test. One-tailed analyses were applied in accordance } \\
\text { with our hypothesis: we expected Parkinson's disease patients to be significantly impaired } \\
\text { compared with controls. Two-tailed analyses did not alter our main findings (data not } \\
\text { shown). } \\
\text { †One patient was excluded from the analysis because the data could not be analysed. } \\
\text { †Errors were calculated by the addition of the number of hits and false alarms. } \\
\text { Variables in italics are the variables of interest. }\end{array}$} \\
\hline
\end{tabular}

significantly more errors. In the 2-back condition, the mean reaction time for $\mathrm{PD}$ group was significantly slower than that of the control group $(F(1,48)=4.79, p=0.033)$. Similarly, the mean error for PD group was significantly higher than in the control group $(\mathrm{F}(1,48)=5.15, \mathrm{p}=0.030)$.

Flexibility: plus-minus task

Although PD patients were significantly slower than controls to complete lists in all conditions, there was no significant difference between the two groups in shift cost (table 2).

Information-processing speed: Stroop test

In the Stroop colour-naming condition, the patients were not significantly impaired, compared with controls.

\section{Performances on driving simulator tasks}

Updating, flexibility and information-processing speed task performances are presented in table 3 . Significant differences were recorded between the two groups for the updating score: $\mathrm{PD}$ patients recalled significantly fewer road signs than controls. In the flexibility task, patients were significantly slower than controls in the condition with alternation. However, flexibility cost did not differ between the two groups. Moreover, in the information-processing speed task, while patients were significantly slower in static and dynamic conditions, there was no difference in information-processing cost between the two groups.

\section{Driving speed and speed variability}

Results for mean speed and speed variability in PD and controls during updating and flexibility tasks are presented in table 4. There were no significant differences between groups except in updating task: speed variability was surprisingly lower in patients compared with controls.

We further examined the effect of updating and flexibility tasks on driving speed and speed variability independently from disease effect. This showed that participants (both patients and

Table 3 Comparison of cognitive performances in Parkinson's disease patients and controls in driving simulator tasks

\begin{tabular}{|c|c|c|c|}
\hline & $\begin{array}{l}\text { Parkinson's } \\
\text { disease } \\
\text { patients, } \\
n=25 \text {, } \\
\text { mean (SD) }\end{array}$ & $\begin{array}{l}\text { Controls, } \\
n=25 \text {, } \\
\text { mean (SD) }\end{array}$ & $\begin{array}{l}\text { One-tail } \\
\text { p-value }\end{array}$ \\
\hline \multicolumn{4}{|l|}{ Updating task } \\
\hline Free recall (1) & $18.7(4.0)$ & $21.3(3.3)$ & 0.007 \\
\hline Cued recall (2) & $19.4(3.7)$ & $21.8(2.6)$ & 0.006 \\
\hline Updating score $(1)+(2)$ & $38.1(7.2)$ & $43.1(4.7)$ & 0.003 \\
\hline \multicolumn{4}{|l|}{ Flexibility task $†$} \\
\hline \multicolumn{4}{|l|}{ Condition without alternation } \\
\hline Response time (ms) (3) & $2483.5(1163.1)$ & 2045.7 (953.9) & 0.054 \\
\hline \multicolumn{4}{|l|}{ Condition with alternation } \\
\hline Response time (ms) (4) & $2602.6(1059.4)$ & $2144.3(848.0)$ & 0.025 \\
\hline Flexibility cost (4)-(3) & $119.1(475.4)$ & $98.6(464.3)$ & 0.356 \\
\hline \multicolumn{4}{|l|}{ Information-processing speed task } \\
\hline $\begin{array}{l}\text { Static condition reaction } \\
\text { time (ms) (5) }\end{array}$ & $695.8(120.3)$ & $639.0(84.5)$ & 0.030 \\
\hline $\begin{array}{l}\text { Dynamic condition reaction } \\
\text { time }(\mathrm{ms})(6)\end{array}$ & $772.3(153.7)$ & $704.6(131.1)$ & 0.040 \\
\hline Information-processing cost (6)-(5) & $76.5(150.9)$ & $65.7(89.0)$ & 0.280 \\
\hline
\end{tabular}

Variables in italics are the variables of interest. Values in bold are significant. *Student $t$ test or Mann-Whitney U test. One-tailed analyses were applied in accordance with our hypothesis: we expected Parkinson's disease patients to be significantly impaired compared with controls. Two-tailed analyses did not alter our main findings (data not shown). †Two patients were excluded from the analysis because their data could not be analysed. 
Table 4 Comparison of Parkinson's disease patients and controls on mean speed and speed variability in updating and flexibility tasks

\begin{tabular}{|c|c|c|c|}
\hline & $\begin{array}{l}\text { Parkinson's } \\
\text { disease patients, } \\
\mathrm{n}=25 \text {, mean (SD) }\end{array}$ & $\begin{array}{l}\text { Controls, } n=25, \\
\text { mean }(S D)\end{array}$ & $\begin{array}{l}\text { One-tailed } \\
\text { p-value* }\end{array}$ \\
\hline \multicolumn{4}{|l|}{ Updating task } \\
\hline Mean speed (km/h) & $83.3(9.7)$ & $82.4(6.2)$ & 0.365 \\
\hline Speed variability & $8.6(2.7)$ & $10.1(2.6)$ & 0.022 \\
\hline \multicolumn{4}{|l|}{ Flexibility task $†$} \\
\hline \multicolumn{4}{|c|}{ Condition without alternation } \\
\hline Mean speed $(\mathrm{km} / \mathrm{h})$ & $94.6(11.1)$ & $90.6(6.2)$ & 0.099 \\
\hline Speed variability & $7.9(5.8)$ & $6.9(3.3)$ & 0.453 \\
\hline \multicolumn{4}{|c|}{ Condition with alternation } \\
\hline Mean speed $(\mathrm{km} / \mathrm{h})$ & $96.5(15.5)$ & $91.0(6.3)$ & 0.088 \\
\hline Speed variability & $4.7(2.4)$ & $4.4(2.3)$ & 0.341 \\
\hline
\end{tabular}

Values in bold are significant.

*Student $t$ test or Mann-Whitney $\mathrm{U}$ test. One-tailed analyses were applied in accordance with our hypothesis: we expected patients with Parkinson's disease to be significantly impaired compared with controls. Two-tailed analyses did not alter our main findings (data not shown).

†Two patients were excluded from the analysis because their data could not be analysed.

controls) had a significantly slower mean driving speed (82.87 \pm 8.07 vs 93.61 \pm 11.85$)(\mathrm{W}=-5.04 \mathrm{p}<0.01)$ and higher speed variability $(9.36 \pm 2.77$ vs $4.55 \pm 2.33)(\mathrm{W}=-3.54 \mathrm{p}<0.01)$ in the updating task than in the flexibility task (condition with alternation). In addition, in the flexibility task, also for all participants, the mean speed did not differ between the two conditions (condition with or without alternation) whereas speed variability decreased significantly in the condition with alternation $(\mathrm{W}=-4.55 \mathrm{p}<0.01)$.

\section{Correlation analyses in PD patients}

UPDRS motor scores did not correlate significantly with updating scores, flexibility cost scores and the processing cost scores. Updating scores on the driving simulator correlated significantly with the following neuropsychological variables: Stroop inhibition cost index $(\mathrm{r}=-0.513, \mathrm{p}<0.01)$, TMT $(\mathrm{B}-\mathrm{A})$ $(\mathrm{r}=-0.560, \mathrm{p}<0.01)$, plus - minus task shift cost $(\mathrm{r}=-0.571$, $\mathrm{p}<0.01)$ and reaction times in the three conditions of the $n$-back task (0-back: $r=-0.428$; 1-back: $r=0.413$; 2-back: $r=-0.394$, $\mathrm{p}<0.05)$. No significant correlations were obtained between Benton Visual Retention Test scores, digit span scores and TMT A scores. Subsequently, only measures which correlated significantly with updating scores were entered in the stepwise regression model. According to this model, TMT (B-A) explained $40.7 \%$ of the variation in updating score on the simulator test. The remaining variables were not sufficiently significant to be included in the model.

\section{DISCUSSION}

The main purpose of this study was to assess the extent to which executive functions such as the updating of information in working memory and mental flexibility are affected in drivers with mild to moderate PD. Our approach was original in that it attempted to examine these functions while driving with a simulator. In this discussion, we shall first of all examine the updating impairment found in PD patients. We will go on to comment on the absence of any flexibility effect and to discuss this dissociation. Finally, we will consider the clinical implications of these results in the context of driving.

\section{Updating}

Both neuropsychological and simulator tests revealed impaired updating in PD patients. In the n-back task, results indicated that the patients perform significantly worse than controls when working memory load increases. The fact that patients are significantly impaired on the 2-back condition is consistent with previous reports. ${ }^{32} 33$ The results obtained on the n-back task corroborate the findings in the updating task on the simulator: patients recalled significantly fewer road signs than controls. However, the possible existence of a relationship between a deficit in updating and a slowing in information processing is not supported by the current results. ${ }^{34}$ Although patients are generally slower, the results observed on the Stroop colournaming test and in the information-processing speed task suggest that information-processing speed was not affected in mild to moderate PD drivers compared with controls. In addition, the updating deficit in PD patients is not due to decreased storage abilities. Verbal short-term storage, measured by digit span, remains intact in our patients, and this is coherent with previous results. ${ }^{13}$ Furthermore, according to Baddeley's model of working memory, ${ }^{35-37}$ updating appears to require two independent mechanisms: the phonological loop involving the maintenance of task-relevant information, and a central executive component. The updating deficit observed in our study cannot be explained by an information maintenance deficit: PD patients' digit span, as measured by Baddeley's Working Memory dual task, is not significantly different from that of the control group. The updating deficit would appear, therefore, to stem from a central executive dysfunction. This hypothesis is consistent with our regression analysis results. Indeed, the TMT $(B-A)$, considered in our study as a measure of global executive function, appears to be the best predictor of updating score in the simulator for PD drivers. This means that the updating task on the simulator is closely linked to the executive system. It is worth noting that the TMT is often reported as being a good predictor of driving performances ${ }^{14} 152930$ and driving cessation for PD drivers. ${ }^{12}$ Our research confirms the usefulness of this test for clinicians in the assessment of PD drivers.

\section{Flexibility}

Contrary to the updating function, flexibility is found to be unimpaired in PD patients compared with controls in both the plus-minus task and the flexibility task on the simulator. A limited power due to the small sample size might explain the absence of difference between groups on tests assessing flexibility. This could also be attributed to our selective inclusion criteria. Participants were only included if they were active drivers, and most of our patients were at relatively early stages of the disease compared with those in other studies. ${ }^{6} 1638$ Alternatively, our flexibility task might not be demanding enough to discriminate between the two groups. Several authors have in fact shown that an impairment in shifting only appears in PD patients when the load of attentional resources increases. 61538 The dissociation observed between updating and flexibility tends to support the conceptual view that the executive component can be fractioned. ${ }^{11} 39$

\section{Driving speed and speed variability}

In addition to cognitive performance obtained on driving simulator tasks (eg, total recall score, reaction times), we analysed mean driving speed and speed variability. ${ }^{15}$ 29-31 Interestingly, for all participants, the mean driving speed was slower, and the speed variability was higher in the updating task than in the flexibility task (condition with alternation). This result suggests poorer driving abilities in the updating task. ${ }^{15}$ This task would appear, therefore, to have a greater impact on driving performances. In the flexibility task, speed variability in both groups decreased significantly in the condition with 
alternation (in which the flexibility mechanism was required). This means that both groups adapt their driving behaviour by reducing speed variability. ${ }^{31}$ Obviously, these results concern only speed measures; other vehicle control measures may well be reported in future research.

\section{Conclusions and clinical implications}

There is clear evidence that updating function is affected in active drivers with mild to moderate $\mathrm{PD}$. According to the literature, updating is an important executive process which might be related to more complex executive functions such as goal management or planning. ${ }^{11} 40$ Uc et al have shown that in real driving contexts, PD patients experience planning difficulties which affect driving performances. ${ }^{29}$ These difficulties could stem from specific updating impairment. This hypothesis could be tested in future research in order to examine the impact of the updating function in drivers with PD in real driving situations. In addition, these findings may have important clinical implications which ought to be taken into consideration by health professionals. Our work confirms that the TMT is a relevant neuropsychological assessment tool for clinicians in the evaluation of PD drivers. Moreover, the use of driving simulators could provide valuable data for predicting driving performances and for observing adjustments in driving behaviour, especially in drivers with mild to moderate PD.

Acknowledgements We would like to thank M-F Boyer for her contribution to the inclusion of all participants. Many thanks are also due to participants of the study. Without their generous support, the study would not have been possible.

\section{Competing interests None.}

Patient consent Obtained.

Ethics approval Ethics approval was provided by the Biomedical Ethics Committee, Lyon, France.

Provenance and peer review Not commissioned; externally peer reviewed.

\section{REFERENCES}

1. Cooper JA, Sagar HJ, Jordan N, et al. Cognitive impairment in early, untreated Parkinson's disease and its relationship to motor disability. Brain 1991:114:2095-122.

2. Muslimovic D, Post B, Speelman JD, et al. Cognitive profile of patients with newly diagnosed Parkinson disease. Neurology 2005:65:1239-45.

3. Gilbert B, Belleville $S$, Bherer $L$, et al. Study of verbal working memory in patients with Parkinson's Disease. Neuropsychology 2005;19:106-14.

4. Lewis SJ, Cools R, Robbins TW, et al. Using executive heterogeneity to explore the nature of working memory deficits in Parkinson's disease. Neuropsychologia 2003:41:645-54.

5. Cronin-Golomb A, Corkin S, Growdon JH. Impaired problem solving in Parkinson's disease: impact of a set-shifting deficit. Neuropsychologia 1994;32:579-93.

6. Cools R, Barker RA, Sahakian BJ, et al. Mechanisms of cognitive set flexibility in Parkinson's disease. Brain 2001:124:2503-12.

7. Bokura H, Yamaguchi S, Kobayashi S. Event-related potentials for response inhibition in Parkinson's disease. Neuropsychologia 2005;43:967-75.

8. Postle BR, Locascio JJ, Corkin S, et al. The time course of spatial and object learning in Parkinson's disease. Neuropsychologia 1997;35:1413-22.

9. Stuss DT. Biological and psychological development of executive functions. Brain Cogn 1992;20:8-23.

10. Heikkila VM, Turkka J, Korpelainen J, et al. Decreased driving ability in people with Parkinson's disease. J Neurol Neurosurg Psychiatry 1998;64:325-30.
11. Miyake A, Friedman NP, Emerson MJ, et al. The unity and diversity of executive functions and their contributions to complex 'Frontal Lobe' tasks: a latent variable analysis. Cogn Psychol 2000;41:49-100.

12. Lafont S, Laumon B, Helmer C, et al. Driving cessation and self-reported car crashes in older drivers: the impact of cognitive impairment and dementia in a population-based study. J Geriatr Psychiatry Neurol 2008;21:171-82

13. Singh R, Pentland B, Hunter J, et al. Parkinson's disease and driving ability. J Neurol Neurosurg Psychiatry 2007;78:363-6.

14. Uc EY, Rizzo M, Anderson SW, et al. Impaired visual search in drivers with Parkinson's disease. Ann Neurol 2006;60:407-13.

15. Uc EY, Rizzo M, Anderson SW, et al. Driving with distraction in Parkinson disease Neurology 2006;67:1774-80.

16. Homann CN, Suppan K, Homann B, et al. Driving in Parkinson's disease-a health hazard? J Neurol 2003:250:1439-46.

17. Dubinsky RM, Gray C, Husted D, et al. Driving in Parkinson's disease. Neurology 1991:41:517-20.

18. Zesiewicz TA, Cimino CR, Malek AR, et al. Driving safety in Parkinson's disease. Neurology 2002;59:1787-8.

19. Lafont S, Marin-Lamellet C, Paire-Ficout L, et al. The Wechsler Digit Symbol Substitution Test as the best indicator of the risk of impaired driving in Alzheimer disease and normal aging. Dement Geriatr Cogn Disord 2010;29:154-63.

20. Revonsuo A, Portin R, Koivikko L, et al. Slowing of information processing in Parkinson's Disease. Brain Cogn 1993;21:87-110.

21. Gibb WR, Lees AJ. The significance of the Lewy body in the diagnosis of idiopathic Parkinson's disease. Neuropathol Appl Neurobiol 1989;15:27-44.

22. Fahn S, Elton RL. Members of the UPDRS development committee: unified Parkinson's disease rating scale. In: Fahn S, Marsden CD, Calne DB, et al. eds. Recent developments in Parkinson's disease. Florham Park, NJ: Macmillan Healthcare information, 1987:153-63.

23. Reitan R. Validity of the trail making test as an indicator of organic brain damage Percept Mot Skills 1958:8:271-6.

24. Azouvi P, Didic-Hamel Cooke M, Fluchaire I, et al. L'évaluation des fonctions exécutives en pratique clinique. Revue de Neuropsychologie 2001:11:383-433.

25. Benton A. Manuel pour l'application du test de rétention visuelle. Applications cliniques et expérimentales. Paris, France: Centre de Psychologie Appliquée, 1965.

26. Baddeley A, Della Sala S, Gray C, et al. Testing central executive functioning with a pencil-and-paper test. In: Rabbit P, ed. Methodology of Frontal and Executive Function. Hove: Psychology Press, 1997:61-80.

27. Zimmermann P, Fimm B. A test battery for attentional performance. In: Leclercq $M$ Zimmermann P, eds. Applied Neuropsychology of Attention: Theory, Diagnosis and Rehabilitation. New York: Psychology Press, 2002:110-51.

28. Etienne V. Executive functions and driving. Study in normal ageing and Alzheimer's disease, PhD thesis. University of Lyon, 2008:1-265.

29. Uc EY, Rizzo M, Anderson SW, et al. Impaired navigation in drivers with Parkinson's disease. Brain 2007:130:2433-40.

30. Stolwyk RJ, Charlton JL, Triggs TJ, et al. Neuropsychological function and driving ability in people with Parkinson's disease. J Clin Exp Neuropsychol 2006;28:898-913.

31. Stolwyk RJ, Triggs TJ, Charlton JL, et al. Effect of a concurrent task on driving performance in people with Parkinson's disease. Mov Disord 2006:21:2096-100.

32. Kensinger EA, Shearer DK, Locascio JJ, et al. Working memory in mild Alzheimer's disease and early Parkinson's disease. Neuropsychology 2003;17:230-9.

33. Altgassen M, Phillips L, Kopp U, et al. Role of working memory components in planning performance of individuals with Parkinson's disease. Neuropsychologia 2007:45:2393-7

34. Salthouse TA. The processing-speed theory of adult age differences in cognition. Psychol Rev 1996;103:403-28.

35. Baddeley A. Working Memory. Oxford: Oxford University Press, 1986

36. Friedman NP, Miyake A, Corley RP, et al. Not all executive functions are related to intelligence. Psychol Sci 2006;17:172-9.

37. Morris $\mathbf{N}$, Jones DM. Memory updating in working memory: the role of the centra executive. Br J Psychol 1990;81:111-21.

38. Witt K, Daniels C, Schmitt-Eliassen J, et al. The impact of normal aging and Parkinson's disease on response preparation in task-switching behavior. Brain Res 2006;1114:173-82

39. Baddeley AD. Exploring the central executive. O J Exp Psychol 1996;49A:5-28.

40. Harvey PO, Le Bastard G, Pochon JB, et al. Executive functions and updating of the contents of working memory in unipolar depression. J Psychiatr Res 2004;38:567-76. 